\title{
Bioimaging of metallothioneins in ocular tissue sections by LA-ICP-MS using bioconjugated gold nanoclusters as specific tags
}

María Cruz-Alonso ${ }^{1}$, Beatriz Fernandez ${ }^{1,2} *$, Lydia Álvarez ${ }^{2}$, Héctor GonzálezIglesias $^{2,3^{*}}$, Heike Traub ${ }^{4}$, Norbert Jakubowski ${ }^{4}$ and Rosario Pereiro ${ }^{1,2}$

${ }^{1}$ Dept. of Physical and Analytical Chemistry, University of Oviedo, Julian Claveria 8, 33006 Oviedo, Spain

${ }^{2}$ Instituto Universitario Fernández-Vega, Fundación de Investigación Oftalmológica, Universidad de Oviedo, Spain.

${ }^{3}$ Instituto Oftalmológico Fernández-Vega, Avda. Dres. Fernández-Vega, 34, 33012 Oviedo, Spain.

${ }^{4}$ Bundesanstalt für Materialforschung und -prüfung (BAM), Richard-WillstaetterStrasse 11, 12489 Berlin, Germany

*Authors to whom correspondence should be addressed

fernandezbeatriz@uniovi.es, hgonzalez@fio.as 


\begin{abstract}
An immunohistochemical method is described to visualize the distribution of metallothioneins 1/2 (MT 1/2) and metallothionein 3 (MT 3) in human ocular tissue. It is making use of (a) antibodies conjugated to gold nanoclusters (AuNCs) acting as labels, and (b) laser ablation (LA) coupled to inductively coupled plasma - mass spectrometry (ICP-MS). Water-soluble fluorescent AuNCs (with an average sized of 2.7 $\mathrm{nm}$ ) were synthesized and then conjugated to antibody by carbodiimide coupling. The surface of the modified AuNCs was then blocked with hydroxylamine to avoid nonspecific interactions with biological tissue. Immunoassays for MT 1/2 and MT 3 in ocular tissue sections (5 $\mu \mathrm{m}$ thick) from two post mortem human donors were performed. Imaging studies were then performed by fluorescence using confocal microscopy, and LA-ICP-MS was performed in the retina to measure the signal for gold. Signal amplification by the $>500$ gold atoms in each nanocluster allowed the antigens (MT 1/2 and MT 3) to be imaged by LA-ICP-MS using a laser spot size as small as $4 \mu \mathrm{m}$. The image patterns found in retina are in good agreement with those by conventional fluorescence immunohistochemistry which was used as a well stablished reference method.
\end{abstract}

KEYWORDS: Metal nanoclusters; Fluorescence; Protein imaging; Thin tissue sections; Immunohistochemistry; Bioconjugation; Carbodiimide crosslinking; Laser ablation; Mass spectrometry. 


\section{INTRODUCTION}

Metallothioneins (MTs) are a family of low molecular mass (6-7 kDa), cysteine-rich $(30 \%)$ and metal-binding proteins [1]. Four major isoforms, named as MT 1-4, have been identified in mammals so far. Cysteine residues can coordinate different metal ions such as $\mathrm{Zn}, \mathrm{Cu}$ and $\mathrm{Cd}$ via thiolate bonds [2]. A wide range of functions including transport and storage of essential metal ions, detoxification of metals and defense against oxidative damage have been reported for this family of proteins [3].

In the human eye, the main sources of oxidative stress are the daily exposure to sunlight, the special microenvironment with abundant photo-sensitizers, and chemical insults [4]. Oxidative stress and MTs-based antioxidant properties, mediated by $\mathrm{Zn}$ in a redox-dependent fashion, have been associated in several ocular diseases [5]. MTs have been suggested to play a key role in protection of neuronal retinal cells [6]. The retina is an ocular tissue highly sensitive to oxidative damage and is composed by several layers of neurons interconnected by synapses (see Fig. 1). Each retinal layer of cells performs specific functions, so it is expected that the expression profile of proteins, including MTs, is different between layers.

The study of the relationship between Zn and MTs in human eye sections requires highly sensitive analytical tools permitting the simultaneous localization (bioimaging) of metals and proteins. Mass spectrometry (MS) techniques show a high potential for the analysis of metalloproteins because they can provide elemental and molecular information necessary to understand the roles of proteins in biological systems [7,8]. Laser ablation (LA) coupled to inductively coupled plasma (ICP)-MS is currently regarded as a versatile inorganic tool for trace element and isotopic analysis of solids. Among the most interesting analytical features of LA-ICP-MS are its sensitivity in the $\mu \mathrm{g} \cdot \mathrm{g}^{-1}-\mathrm{ng} \cdot \mathrm{g}^{-1}$ range (depending on the experimental conditions employed) and a spatial resolution in the $\mu \mathrm{m}$ range. LA-ICP-MS has shown a huge potential for elemental imaging studies in biological tissues $[9,10]$.

Immunoassays are based on the specific recognition of antigens with their corresponding antibodies $(\mathrm{Ab})$. Mapping of proteins in biological tissues can be carried out by LA-ICP-MS using metal-tagged immunoprobes. High multiplexing and quantification capabilities are main advantages brought about by such a combination. Single metal chelates, e.g. 1,4,7,10-tetraazacyclododecane-1,4,7,10-tetraacetic acid (also known as DOTA) coordinated with heteroatoms (typically lanthanide ions), have 
been described for elemental tagging [11,12]. The use of polymeric tags (containing metal chelates) providing signal amplification was also reported $[13,14]$. Here, it should be highlighted the interesting capabilities reported for LA coupled to mass cytometry, where the use of such tags combined to a fast-washout ablation cell and a time of flight mass spectrometer provides high lateral resolution as well as high multiplexing capabilities $[15,16]$.

However, these labels are composed of a polymeric non-metallic part, giving rise to a relatively high size. Moreover, risk of unspecific interactions has been reported [17]. Such inconvenience can be overcome by Ab tagging with metallic clusters. As compared to metal-containing polymeric tags, the "number of metal atoms/tag size" ratio can be higher, so that high amplification can be achieved with a smaller size. The combined use of Au nanoparticles labelled antibody and ICP-MS detection has proved to be an interesting strategy for immunoassays detection in liquid samples [18].

The use of metallic nanoparticles or nanoclusters combined to LA-ICP-MS is still scarce. $10 \mathrm{~nm}$ Au nanoparticles were employed in blotting membranes after protein separation by SDS-PAGE [19]. Bioimaging experiments were carried out for breast cancer biomarkers using $5 \mathrm{~nm}$ Au labelled secondary antibody [20]. Also, this protein tagging approach, based on the use of a secondary IgG antibody (labelled with $10 \mathrm{~nm}$ $\mathrm{Au}$ nanoparticles), was employed for bioimaging of dopamine-producing enzyme tyrosine hydroxylase in brain [21].

Gold nanoclusters (AuNCs) are composed of a few to some hundreds metal atoms, with size between 0.2 and $3 \mathrm{~nm}$. Therefore, these small labels can provide high signal amplification as elemental tags in LA-ICP-MS bioimaging. Moreover, there will be no accessibility restrictions to the sought protein within the tissue (this is one of the problems associated with larger labels). On the other hand, this metal NCs offer new optical characteristics (e.g. fluorescence) with respect to bigger nanoparticles and bulk material [22,23]; in this way, it can be obtained fluorescent and LA-ICP-MS images in the same tissue section.

In this work, fluorescent AuNCs are synthesized and bioconjugated with specific primary antibodies via carbodiimide crosslinking. This format offers potential advantages as compared to the use of a secondary antibody labelled with gold nanoparticles previously described [19-21]. For example, fewer reagents and simpler immunohistochemical procedures are required since it is not needed a secondary antibody. Also high multiplexing capabilities can be achieved using a different type of 
metal isotope nanocluster per specific $\mathrm{Ab}$ (e.g. NCs of $\mathrm{Pt}$ or $\mathrm{Ag}$ ). Finally, the fluorescence of the AuNCs makes easier and simpler the optimization procedures as well as it can serve as a preliminary fast checking. As a proof of concept, in this article an immunohistochemical procedure employing the AuNCs label was applied to specific bioimaging of metallothioneins in ocular tissue sections (retina region). A conventional immunohistochemistry procedure in adjacent tissue sections was performed to validate images.

\section{EXPERIMENTAL}

\section{Chemicals and materials}

Chemicals and reagents were of analytical grade. All solutions were prepared with Milli-Q water (Millipore; http://www.merckmillipore.com). $\mathrm{AuCl}_{4} \mathrm{Na} \cdot \mathrm{H}_{2} \mathrm{O}$ (99\% powder; Sigma-Aldrich; https://www.sigmaaldrich.com), lipoic acid (> 98\% powder; Across Organics; http://www.acros.com/) and $\mathrm{NaBH}_{4}$ (> 98\% powder, Sigma-Aldrich) were employed for the synthesis of AuNCs.

Immunoassays in the human eye tissue sections were performed either with a primary monoclonal anti-MT $1 / 2$ antibody (produced in rabbit; Abcam; http://www.abcam.com) or with a primary anti-MT 3 antibody (produced in mouse; Sigma-Aldrich). 1-Ethyl-3-(3-dimethylaminopropyl) carbodiimide (EDC) (98\% powder; Across Organics) and N-hydroxysuccinimide (NHS) (95\% powder; Thermo Fisher Scientific; https://www.thermofisher.com) were used in the bioconjugation procedure. To reduce unspecific interactions, hydroxylamine hydrochloride $(\geq 99 \%$ powder; Sigma-Aldrich) was employed at the last step of the bioconjugation procedure. Amicon ultra centrifugal filter units (10 and $100 \mathrm{kDa}$ size, Millipore) were used for purification.

Human eye globes from adult donors were obtained $24 \mathrm{~h}$ post mortem through the National Disease Research Interchange (Philadelphia, USA), formalin fixed and paraffin embedded (FFPE), following conventional protocols. The procedures adhered to the tenets of the Declaration of Helsinki. $5 \mu \mathrm{m}$ thick eye tissue sections from FFPE blocks were placed in FLEX coated microscope slides (IHC Microscope slides, Agilent Technologies; http://www.agilent.com). Deparaffinization was done with xylene (Sigma-Aldrich) and ethanol (VWR Chemicals; https://us.vwr.com). Target retrieval 
solutions, pH 9 and pH 6 (10x) (Agilent Technologies) were used for antigen retrieval. EnVision $^{\text {TM }}$ FLEX commercial kit (Agilent technologies) was employed for conventional immunohistochemistry in experiments related with optimization of the retrieval procedure.

Ammonium chloride (Panreac AppliChem; https://www.itwreagents.com) to minimize tissue autofluorescence, and triton X-100 (Sigma-Aldrich) to permeabilize tissue sections, were used. Bovine serum albumin (BSA) (99\% powder, Merck KGaA; https://www.merckgroup.com) and goat serum (Sigma-Aldrich) were employed as blocking agents during immunoassay procedures. Washing steps were conducted with phosphate buffered saline (10 mM PBS-0.9\% NaCl, pH 7.4) (Sigma-Aldrich).

Validation of our methodology was carried out, in adjacent tissue slices, by conventional fluorescence immunohistochemistry with goat anti-mouse $\operatorname{IgG}(\mathrm{H}+\mathrm{L})$ highly cross-adsorbed secondary antibody labelled with Alexa Fluor 594 for MT 1/2 primary antibody, or with goat anti-rabbit $\operatorname{IgG}(\mathrm{H}+\mathrm{L})$ highly cross-adsorbed secondary antibody labelled with Alexa Fluor 594 (both from Thermo Fisher Scientific) for MT 3 primary antibody. 4'6-Diamidino-2-phenylindole dihydrochloride (DAPI) (Thermo Fisher Scientific) was used to stain the cell nucleus. Mounting media specific for fluorescence detection (Agilent Technologies) was also employed to protect the tissue and maintain the fluorescence signal during microscopy visualization.

\section{Synthesis of AuNCs}

Synthesis of AuNCs was carried out in a fume hood (using protecting gloves, security glasses and breathing mask) following an approach previously described [24] and it is described in the Electronic Supporting Material (ESM). Experimental results showed an average particle size of $2.7 \pm 0.1 \mathrm{~nm}$ (200 individual values were measured by HR-TEM). Au measurement by ICP-MS combined with size, geometry and crystal structure of AuNCs (obtained by HR-TEM) showed that each nanocluster is composed of 579 atoms of Au on average [24]. 
Synthesis of anti-human MT 1/2-AuNCs and anti-human MT 3-AuNCs bioconjugates.

Bioconjugation was carried out following a protocol previously described for fluorescent determination of immunoglobulin E (IgE) in solution using AuNCs [24]. $100 \mu \mathrm{L}$ of anti-human MT 1/2 antibody $\left(100 \mu \mathrm{g} \cdot \mathrm{mL}^{-1}\right)$, or anti-human MT 3 antibody $\left(100 \mu \mathrm{g} \cdot \mathrm{mL}^{-1}\right)$, were added to an Eppendorf tube at room temperature followed by 283 $\mu \mathrm{L}$ of AuNCs solution (1:3 molar ratio of Ab:AuNCs). Then, mechanical stirring was started and the EDC and NHS reagents were added; EDC was in excess, in a molar ratio of $\mathrm{Ab}$ :EDC of 1:1500, while the added NHS amount was related to the amount of EDC (so that they were in a EDC:NHS molar ratio of 1:1). After $2 \mathrm{~h}$ at room temperature with constant stirring, purification was performed by ultrafiltration $(100 \mathrm{kDa}$ pore size Amicon).

An additional last step to reduce nonspecific interactions was carried out. The bioconjugates were incubated with hydroxylamine hydrochloride (in a 1:20 AuNCs:hydroxylamine molar ratio). After $2 \mathrm{~h}$ at room temperature with constant stirring, the excess of hydroxylamine was removed by ultrafitration: the centrifugation sequence (with $100 \mathrm{kDa}$ pore size Amicon) consisted of a first cycle at $700 \mathrm{~g}$ for $7 \mathrm{~min}$ and two washing steps with water at $700 \mathrm{~g}$ for $7 \mathrm{~min}$. The final purified solutions were stored at $4{ }^{\circ} \mathrm{C}$.

Immunoassay protocol with the bioconjugated AuNCs for detection by LA-ICPMS and by fluorescence

Eye tissue sections ( $5 \mu \mathrm{m}$ thick) from FFPE blocks were deposited on FLEX coated microscope slides. Slides were incubated for $60 \mathrm{~min}$ at $56{ }^{\circ} \mathrm{C}$ and afterwards immersed in target retrieval solution ( $\mathrm{pH} 9$ ) at $95^{\circ} \mathrm{C}$ for $20 \mathrm{~min}$. After the paraffin was removed, tissue sections were washed three times $(10 \mathrm{~min})$ with $10 \mathrm{mM}$ PBS pH 7.4. Then, $0.1 \%$ triton X-100 in PBS was added to slides for $5 \mathrm{~min}$. A further washing step with PBS was necessary, and then the blocking agent solution $(0.1 \%$ BSA and $10 \%$ goat serum solution in $10 \mathrm{mM}$ PBS, $\mathrm{pH}$ 7.4) was added and kept at room temperature for $30 \mathrm{~min}$. Subsequently, the bioconjugate $\left(10 \mu \mathrm{g} \cdot \mathrm{mL}^{-1}\right)$ was added and incubated overnight at 4 ${ }^{\circ} \mathrm{C}$. 
After this incubation, a washing step with PBS was done. In the case of fluorescence detection, after the washing step with PBS, the tissue was incubated for $10 \mathrm{~min}$ at room temperature in darkness with DAPI solution, to stain the cell nucleus. Finally, they were washed with PBS, immersed in fluorescence mounting media and the cover glass was added. They were dried for $1 \mathrm{~h}$ and then stored at $-20{ }^{\circ} \mathrm{C}$. After fluorescence measurement, the cover glass is removed and analysis by LA-ICP-MS is carried out.

\section{Immunoassay protocol for validation of the methodology}

For validation with conventional immunohistochemistry, in adjacent tissue sections, the primary antibody (anti-MT 1/2 or anti-MT 3) was added and incubated overnight at $4{ }^{\circ} \mathrm{C}$ in $5 \mu \mathrm{m}$ thick FFPE eye tissues previously treated and blocked as in the protocol with AuNCs. After incubation with the primary antibody, a washing step with PBS was done. Then, the corresponding Alexa Fluor 594 labelled secondary antibodies (see chemicals and materials section), diluted 1:400 in a PBS buffer containing 0.1\% BSA + $10 \%$ goat serum, was added and incubated at $37{ }^{\circ} \mathrm{C}$ for $1 \mathrm{~h}$. Further steps, as nucleus staining and storage conditions, were the same as those for fluorescence detection with the bioconjugated AuNCs.

\section{LA-ICP-MS analysis}

LA-ICP-MS measurements were carried out with a commercial LA system (NWR213, ESI, Nd:YAG $213 \mathrm{~nm}$ ) coupled to a double-focusing sector field ICP-MS (Element XR, Thermo Fisher Scientific). The LA-ICP-MS coupling was optimized daily for maximum signal and good stability (relative standard deviation $<5 \%$ ), keeping the oxide ratio $(\mathrm{ThO} / \mathrm{Th}$ ) below $0.5 \%$ during ablation of a microscopic glass slide. NIST 612 was used daily for the determination of the mass offsets. Table S1 (in ESM) collects experimental conditions. Medium resolution $(\mathrm{R}=4,000)$ of the sector field instrument was applied to overcome spectral interferences for the main isotopes of $\mathrm{Cu}$ and $\mathrm{Zn}$ in the samples. In the case of high resolution images, the LA-ICP-MS analysis time ranges between 3 and 4 hours. Two-dimensional images of $\mathrm{Zn}, \mathrm{Cu}$ and $\mathrm{Au}$ (MT 1/2 and MT 3) were created using ImageJ-Fiji software. In the case of high resolution images, the analysis time ranges between 3-4 hours. For data treatment, the gas blank contribution was eliminated from the raw intensity signals to work with net intensities 
(counts per second). With the ImageJ-Fiji, a magnification of the image was applied with a six factor respect to the real size of the image (micrometers dimensions) and a bicubic interpolation was done to eliminate the pixel aspect.

\section{Fluorescence and optical microscopy analyses}

Images from the immunoassays were obtained with a laser confocal microscope (DM IRE2; Leica) with 20x and 40x oil immersion objectives and using a photomultiplier and a hybrid detector. Laser excitation lines of $405 \mathrm{~nm}$ (for bioconjugate and DAPI measurements) and $598 \mathrm{~nm}$ (for conventional immunohistochemistry) were used. Fluorescence image processing was carried out with ImageJ software. Furthermore, optical images of ocular tissues were done by optical transmission microscopy (Olympus BX61, digital camera Olympus DP-70).

\section{RESULTS AND DISCUSSION}

The synthesized AuNCs emit stable fluorescence with a maximum at $710 \mathrm{~nm}$. AuNCs fluorescence was used for fast optimization of both, the bioconjugation steps and the immunohistochemistry procedure.

\section{Optimization of the bioconjugation and immunohistochemistry procedures}

In a previously work describing the fluorescent determination of $\operatorname{IgE}$ in solution using AuNCs [24], the molar ratio between the antibody and AuNCs was optimized aiming at maintaining the expected properties from both components, Ab and AuNCs. In our studies, a 1:3 molar ratio (Ab:AuNCs) was chosen based on a compromise between recognition capabilities of the bioconjugate (measured by ELISA) and its fluorescence intensity. For optimum immunohistochemistry analysis with AuNCs as labels there is an additional step that it is necessary to consider. Bioconjugation procedures consist in the attachment of two molecules usually through a covalent bond. In our case, these molecules are the antibody (with free amine groups) and the AuNCs (with available carboxylic groups). To achieve this covalent bond, first it is necessary to activate the carboxylic group, making use of EDC and NHS. After bioconjugation, the surface of the AuNCs still contains activated carboxyl groups which did not react with the antibody. Therefore, it is necessary to block these remaining functional groups to 
avoid nonspecific interaction with biomolecules in the tissue section and the subsequent high background signal after the immunohistochemical procedure. For such purpose, a primary amine (hydroxylamine) as blocking agent was evaluated in the present work. A 1:20 molar ratio of AuNCs:hydroxylamine was finally chosen (see Figs. S1 and S2 and experiments described in ESM).

Instead of using the traditional immunohistochemical combination of primary and secondary antibodies, in our procedure only the primary antibody was needed (bioconjugated with the AuNCs as elemental tag). The optimization of the deparaffinization procedure is described in ESM. Three different protocols were assayed: xylol treatment, target retrieval solution $\mathrm{pH} 6$, and target retrieval solution $\mathrm{pH}$ 9. Fig. S3 shows pH 9 as optimum. In ESM it is also described experiments related with the selection of the bioconjugate concentration (Fig. S4). $10 \mu \mathrm{g} \cdot \mathrm{mL}^{-1}$ of bioconjugate was chosen for further experiments.

\section{Bioimaging of heteroatoms in ocular tissue sections by LA-ICP-MS: selection of experimental parameters for high resolution images}

To obtain representative information of elemental composition from biological tissues by LA-ICP-MS imaging, experimental conditions must be optimized to ensure a complete ablation of the total tissue thickness. Optimized experimental conditions for the analysis of the retina region are collected in Table S1. As can be seen, three laser beam diameters $(25 \mu \mathrm{m}, 6 \mu \mathrm{m}$ and $4 \mu \mathrm{m})$ were investigated after the immunoassay with AuNCs bioconjugate.

Thanks to the ability of ICP-MS for the multi-element detection of different heteroatoms in the same analysis ${ }^{63} \mathrm{Cu}^{+}$and ${ }^{64} \mathrm{Zn}^{+}$(metal ions that can be coordinated to MTs) were also investigated by LA-ICP-MS in retina using the higher beam diameter $(25 \mu \mathrm{m})$. Fig. 2 shows the elemental images by LA-ICP-MS for ${ }^{197} \mathrm{Au}^{+}$(i.e. bioimaging of MT1/2), ${ }^{63} \mathrm{Cu}^{+}$and ${ }^{64} \mathrm{Zn}^{+}$(Figs. 2b, 2c and 2d, respectively) in ocular tissue section from a post mortem donor (donor \#1). ${ }^{63} \mathrm{Cu}^{+}$and ${ }^{64} \mathrm{Zn}^{+}$signals were monitored to evaluate the possible co-localization between such elements and the Au signal from the protein (MTs bind both, $\mathrm{Cu}$ and $\mathrm{Zn}$ ) [25,26]. Although a similar localization of $\mathrm{Cu}$ and $\mathrm{Zn}$ compared to $\mathrm{Au}$ was observed, the signals for $\mathrm{Zn}$ and $\mathrm{Cu}$ by ICP-MS were low and did not allow to concluding that there is a direct correlation between elemental and molecular images. A possible explanation of this result is the low thickness of the tissue 
sample and the subsequent low availability of enough $\mathrm{Cu}$ and $\mathrm{Zn}$ quantity $(5 \mu \mathrm{m}$ thickness is optimal for immunohistochemistry procedures). Additionally, the different steps required for the immunoassay and bioconjugation with AuNCs as well as the paraffinization and deparaffinization steps probably produce leaching of metals from tissue sections [27]. On the other hand, it should be stated that $\mathrm{Cu}$ and $\mathrm{Zn}$ are not only coordinated to MTs in biological tissues but also to other type of proteins and, therefore, $\mathrm{Au}$ (i.e. MT 1/2) and $\mathrm{Cu}$ and $\mathrm{Zn}$ distributions in LA-ICP-MS images do not have to be exactly the same.

Fig. $2 \mathrm{~b}$ shows the localization of Au with this laser beam diameter of $25 \mu \mathrm{m}$. High intensity signals for ${ }^{197} \mathrm{Au}^{+}$were obtained, which can be attributed to the huge amplification of AuNCs (each nanocluster is composed by an average of 579 atoms of $\mathrm{Au})$. As can be seen, the comparison of this procedure and the conventional immunofluorescence protocol (Figs. $2 \mathrm{f}$ and $2 \mathrm{~g}$ ) for validation purposes, done in parallel tissue cuts, showed a correlation in the localization of MTs along the neurosensory retinal layers, specifically the outer nuclear and inner nuclear layers, as well as the ganglion cells. Fig. S5 (ESM) shows another successful example (donor \#2) of bioimaging of MT 1/2 in neurosensory retina tissue section after immunohistochemistry with AuNCs bioconjugate and LA-ICP-MS detection.

Images by fluorescence microscopy offer a better resolution than those by LAICP-MS. In any case, the distribution of MTs throughout the retinal layers can be well discriminated by LA-ICP-MS (particularly in the images with low laser beam diameters as it will showed in next section). In order to improve the lateral resolution by LA-ICPMS, smaller laser beam diameters were investigated since the neurosensory retina is formed by different layers of low micrometer dimensions. Fig. 3 collects the qualitative elemental image of ${ }^{197} \mathrm{Au}^{+}$(i.e. MT 1/2 using the AuNCs bioconjugate) using $6 \mu \mathrm{m}$ and $4 \mu \mathrm{m}$ as laser beam diameter in three adjacent areas of the same section. As can be seen in Fig. 3b, a $6 \mu \mathrm{m}$ laser beam yields enough ${ }^{197} \mathrm{Au}^{+}$signal intensity to study MT $1 / 2$ position in the retina while improving the spatial resolution as compared to the $25 \mu \mathrm{m}$ laser beam diameter (Fig. 2b and Fig. S5b). Note that in Fig. $3 b$ the ${ }^{197} \mathrm{Au}^{+}$signal has been saturated at the inner nuclear layer to distinguish the MT 1/2 distribution in the other retinal layers with lower protein levels.

As can be seen in Figs $3 \mathrm{c}$ and 3d, MT 1/2 can be clearly identified in the retina using a $4 \mu \mathrm{m}$ laser beam diameter. Additionally, a better image quality as well as signal 
intensities were obtained with $5 \mu \mathrm{m}$ distance between spots (Fig. 3d) compared to $2 \mu \mathrm{m}$ distance (Fig. 3c) for the $4 \mu \mathrm{m}$ laser beam. Although the use of lower distances between lines can improve the resolution, a compromise should be taken to avoid overlapping of lines and, thus, distortion of the images and reduction of the intensity signals.

\section{Study of MT 1/2 and MT 3 localization in the retina by LA-ICP-MS}

The bioimaging methodology based on the use of AuNCs bioconjugates was applied to study MT 1/2 and MT 3 in eye tissue sections from post mortem donors. In order to obtain high resolution images from the retina region, $4 \mu \mathrm{m}$ laser beam diameter was selected.

In Fig. 4 the optical images (Figs. 4a and 4c) of two ocular tissues submitted to AuNCs bioconjugation methodology (MT 1/2 protein) and the qualitative images by LA-ICP-MS for ${ }^{197} \mathrm{Au}^{+}$(Figs. 4b and 4d) are presented from two post mortem donors (donor \#1 and donor \#2). As expected, the position of MT 1/2 was identical to that using $25 \mu \mathrm{m}$ (Figs. 2 and S5). The differences observed are in terms of image definition, allowing the use of the $4 \mu \mathrm{m}$ laser beam for a better understanding of the structural MTs distribution along the different layers of retina. As shown in Fig. 4, MT 1/2 was found to be mainly located in the inner nuclear layer, the outer nuclear layer and in the ganglion cells layer, in both individuals (donors \#1 and \#2). Localization of MT proteins in the human retina has been previously published [5,28]. Expression of different MT isoforms in the developing photoreceptor layer, the outer nuclear layer and the inner nuclear layer of the retina has been reported by other authors [29]. Moreover, MT 1/2 isoforms have been immunolocalized in the inner plexiform and inner nuclear layers [5]. In any case, some differences on MTs distribution along the retinal layers can be attributed to biological differences characteristic for each individual patient.

In order to show that this methodology can be extended to other proteins, MT 3 was also investigated in retina region. Fig. 5 shows the image by LA-ICP-MS for ${ }^{197} \mathrm{Au}^{+}$ (MT 3 protein in this case) at high resolution using $4 \mu \mathrm{m}$ (Fig. 5b). As for the case of MT $1 / 2$, there is a correlation between our imaging LA-ICP-MS methodology and conventional immunohistochemistry (Figs. 5c and 5d), demonstrating the potential of AuNCs bioconjugate for proteins localization by LA-ICP-MS. 


\section{CONCLUSIONS}

The methodology for bioimaging of proteins by LA-ICP-MS, based on the use of metal nanoclusters bioconjugated to antibodies as labels, was evaluated for the localization of MT 1/2 and MT 3 in ocular tissue samples with AuNCs bioconjugates. Unspecific interactions with the tissue were reduced using hydroxylamine as blocking agent.

The elemental LA-ICP-MS images for ${ }^{197} \mathrm{Au}^{+}$showed a good correlation with conventional immunohistochemistry for the proteins investigated, indicating the potential of this new approach. The amplification provided by the AuNCs labels opens the door to obtain highly resolved bioimages using small laser beam diameters.

Nowadays, fluorescence and immunohistochemistry are the preferred methods for proteins localization in thin tissue sections and LA-ICP-MS cannot currently compete with them in terms of spatial resolution. However, LA-ICP-MS analysis offers interesting advantages, such as higher multiplexing capabilities (many different isotopes can be used for the preparation of NCs) and easier quantitative protein bioimaging. Experiments in such directions are presently under way in our laboratory.

\section{ACKNOWLEDGEMENTS}

This work was supported by project CTQ2016-79015-R by Agencia Estatal de Investigación (Spain) and FEDER. M. Cruz-Alonso acknowledges funding received by Zinc-net (COST TD1304) for a STSM at BAM (Germany). B. Fernandez acknowledges her contract RYC-2014-14985 to the Spanish Ministry of Economy and Competitiveness through the "Ramón y Cajal Program". L. Alvarez and H. Gonzalez acknowledge financial support from "Fundación Rafael del Pino" and "Fundación $M^{a}$ Cristina Masaveu Peterson". The authors would like to thank M. Daniela Corte and Pablo Isidro Marrón from the Biobank (HUCA, Oviedo) for antigen retrieval services and Pablo Garcia Manrique for his valuable support in bioconjugation experiments. 


\section{FIGURE CAPTIONS}

Fig. 1. Schematic view of the human neurosensory retina. The mammalian retina (enlarged image) consists of several cell types arranged in a highly organized manner forming distinct layers. PR: Photoreceptors; ONL: Outer Nuclear Layer; OPL: Outer Plexiform Layer; INL: Inner Nuclear Layer; IPL: Inner Plexiform Layer; GC: Ganglion Cells; NFL: Nerve Fiber Layer.

Fig. 2. Analysis of neurosensory retina section (donor \# 1), after immunohistochemistry with AuNCs bioconjugate (MT 1/2). (a) Transmission image before LA; (b) Elemental images by LA-ICP-MS (25 $\mu \mathrm{m}$ spot size) for ${ }^{197} \mathrm{Au}^{+}$; (c) ${ }^{63} \mathrm{Cu}^{+}$; (d) ${ }^{64} \mathrm{Zn}^{+}$; (e) Transmission image; (f) Fluorescence image with secondary antibody; and (g) Fluorescence image with secondary antibody and DAPI.

Fig. 3. (a) Histological image of the human neurosensory retina section analyzed by LA-ICP-MS (donor \#1); (b) Distribution for ${ }^{197} \mathrm{Au}^{+}$(AuNCs bioconjugate with MT 1/2 antibody) using $6 \mu \mathrm{m}$ laser beam and $6 \mu \mathrm{m}$ distance between lines; (c) $4 \mu \mathrm{m}$ laser beam and $2 \mu \mathrm{m}$ distance between lines; and (d) $4 \mu \mathrm{m}$ laser beam and $5 \mu \mathrm{m}$ distance between lines. Note: (a) and (b) belong together, but (c) and (d) are from different areas of the tissue.

Fig. 4. Analysis by LA-ICP-MS of neurosensory retinas from donors \#1 and \#2, after immunohistochemistry with AuNCs bioconjugate for MT 1/2. (a and c) Transmission images; (b and d) Distribution of ${ }^{197} \mathrm{Au}^{+}$(MT 1/2) in the tissue sections.

Fig. 5. Analysis of a neurosensory retina section (donor \#1) after immunohistochemistry protocol with AuNCs bioconjugate (MT 3). (a) LA-ICP-MS image for ${ }^{197} \mathrm{Au}^{+}$using 4 $\mu \mathrm{m}$ spot size; (b) Transmission image; (c) Fluorescence image with secondary antibody; and (d) Fluorescence image with secondary antibody and DAPI. 


\section{REFERENCES}

[1] Eckschlager T, Adam V, Hrabeta J, Figova K, Kizek R (2009) Metallothioneins and cancer. Curr Protein Pept Sci 10:360-375.

[2] Bell DG, Vallee BL (2009) The metallothionein/thionein system: an oxidoreductive metabolic zinc link. Chembiochem 10:55-62.

[3] Maret W, Krężel A (2007) Cellular zinc and redox buffering capacity of metallothionein/thionein in health and disease. Mol Med 13:371-375.

[4] Jarrett SG, Boulton ME (2012) Consequences of oxidative stress in age-related macular degeneration. Mol Aspects Med 33:399-417.

[5] Gonzalez-Iglesias H, Alvarez L, García M, Petrash C, Sanz-Medel A, Coca-Prados M (2014) Metallothioneins (MTs) in the human eye: a perspective article on the zincMT redox cycle. Metallomics 6:201-208.

[6] Suemori S, Shimazawa M, Kawase K, Satoh M, Nagase H, Yamamoto T, Hara H (2006) Metallothionein, an endogenous antioxidant, protects against retinal neuron damage in mice. Invest Ophthalmol Vis Sci 47:3975-3982.

[7] Carerui M, Mangia A (2011) Trends in analytical atomic and molecular mass spectrometry in biology and the life sciences. Anal Bioanal Chem 399:2585-2595.

[8] Lee RFS, Theiner S, Meibom A, Koellensperger G, Keppler BK, Dyson PJ (2017) Application of imaging mass spectrometry approaches to facilitate metal-based anticancer drug research. Metallomics 9:365-381.

[9] Konz I, Fernández B, Fernández ML, Pereiro R, Sanz-Medel A (2012) Laser ablation ICP-MS for quantitative biomedical applications. Anal Bioanal Chem 403:2113-2125.

[10] Pozebon D, Scheffler GL, Dressler VL (2017) Recent applications of laser ablation inductively coupled plasma mass spectrometry (LA-ICP-MS) for biological sample analysis: a follow-up review. J Anal At Spectrom 32:890-919.

[11] Giesen C, Mairinger T, Khoury L, Waentig L, Jakubowski N, Panne U (2011) Multiplexed immunohistochemical detection of tumor markers in breast cancer tissue using laser ablation inductively coupled plasma mass spectrometry. Anal Chem 83:8177-8183.

[12] Kanje S, Herrmann AJ, Hobera S, Mueller L (2016) Next generation of labeling reagents for quantitative and multiplexing immunoassays by the use of LA-ICP-MS. Analyst 141:6374-6380. 
[13] Lou X, Zhang G, Herrera I, Kinach R, Ornatsky O, Baranov V, Nitz M, Winnik MA (2007) Polymer-based elemental tags for sensitive bioassays. Angew Chem Int Ed 46:6111-6114.

[14] Majonis D, Herrera I, Ornatsky O, Schulze M, Lou X, Soleimani M, Nitz M, Winnik MA (2010) Synthesis of a functional metal-chelating polymer and steps toward quantitative mass cytometry bioassays. Anal Chem 82:8961-8969.

[15] Giesen C, Wang HAO, Schapiro D, Zivanovic N, Jacobs A, Hattendorf B, Schüffler PJ, Grolimund D, Buhmann JM, Brandt S, Varga Z, Wild PJ, Günther D, Bodenmiller B (2014) Highly multiplexed imaging of tumor tissues with subcellular resolution by mass cytometry. Nature Methods 11:417-422

[16] Chang Q, Ornatsky OI, Siddiqui I, Loboda A, Baranov VI, Hedley DW (2017) Imaging mass cytometry. Cytometry Part A, 91A:160-169.

[17] Waentig L, Jakubowski N, Hardt S, Scheler C, Roos PH, Linscheid MW (2012) Comparison of different chelates for lanthanide labeling of antibodies and application in a Western blot immunoassay combined with detection by laser. J Anal At Spectrom 27: 1311-1320.

[18] Zhang C, Zhang Z, Binbing B, Shi J, Xinrong Zhang X (2002) Application of the biological conjugate between antibody and colloid $\mathrm{Au}$ nanoparticles as analyte to inductively coupled plasma mass spectrometry. Anal Chem 74:96-99.

[19] Müller SD, Diaz-Bone RA, Felix J, Goedecke W (2005) Detection of specific proteins by laser ablation inductively coupled plasma mass spectrometry (LA-ICP-MS) using gold cluster labelled antibodies. J Anal At Spectrom 20:907-911.

[20] Seuma J, Bunch J, Cox A, McLeod C, Bell J, Murray C (2008) Combination of immunohistochemistry and laser ablation ICP mass spectrometry for imaging of cancer Biomarkers. Proteomics 8:3775-3784.

[21] Paul B, Hare DJ, Bishop DP, Paton C, Nguyen VT, Cole N, Niedwiecki MM, Andreozzi E, Vais A, Billings JL, Bray L, Bush AI, McColl G, Roberts BR, Adlard PA, Finkelstein DI, Hellstrom J, Hergt JM, Woodhead JD, Doble PA (2015) Visualising mouse neuroanatomy and function by metal distribution using laser ablation-inductively coupled plasma-mass spectrometry imaging. Chem Sci 6:5383-5393.

[22] Le Guével X (2014) Recent advances on the synthesis of metal quantum nanoclusters and their application for bioimaging. IEEE J Sel Top Quant 20:45-56. 
[23] Zhang L, Wang E (2014) Metal nanoclusters: New fluorescent probes for sensors and bioimaging. Nano Today 9:132-157.

[24] Alonso MC, Trapiella-Alfonso L, Fernández JMC, Pereiro R, Sanz-Medel A (2016) Functionalized gold nanoclusters as fluorescent labels for immunoassays: application to human serum immunoglobulin E determination. Biosens Bioelectron 77:1055-1061.

[25] Osredkar J, Sustar N (2011) Copper and zinc, biological role and significance of copper/zinc imbalance. J Clinic Toxicol S3:001.

[26] Ugarte M, Osborne NN, Brown LA, Bishop PN (2013) Iron, zinc, and copper in retinal physiology and disease. Surv Ophthalmol 58:585-609.

[27] Hare DJ, George JL, Bray L, Volitakis I, Vais A, Ryan TM, Cherny RA, Bush AI, Masters CL, Adlard A, Doble PA, Finkelstein DI (2014) The effect of paraformaldehyde fixation and sucrose cryoprotection on metal concentration in murine neurological tissue. J Anal At Spectrom 29:565-570.

[28] Lu H, Hunt DM, Ganti R, Davis A, Dutt K, Alam J, Hunt RC (2002) Metallothionein protects retinal pigment epithelial cells against apoptosis and oxidative stress. Exp Eye Res 74:83-92.

[29] Tate DJ, Miceli MV, Newsome DA (2002) Expression of metallothionein isoforms in human chorioretinal complex. Curr Eye Res 24:12-25. 


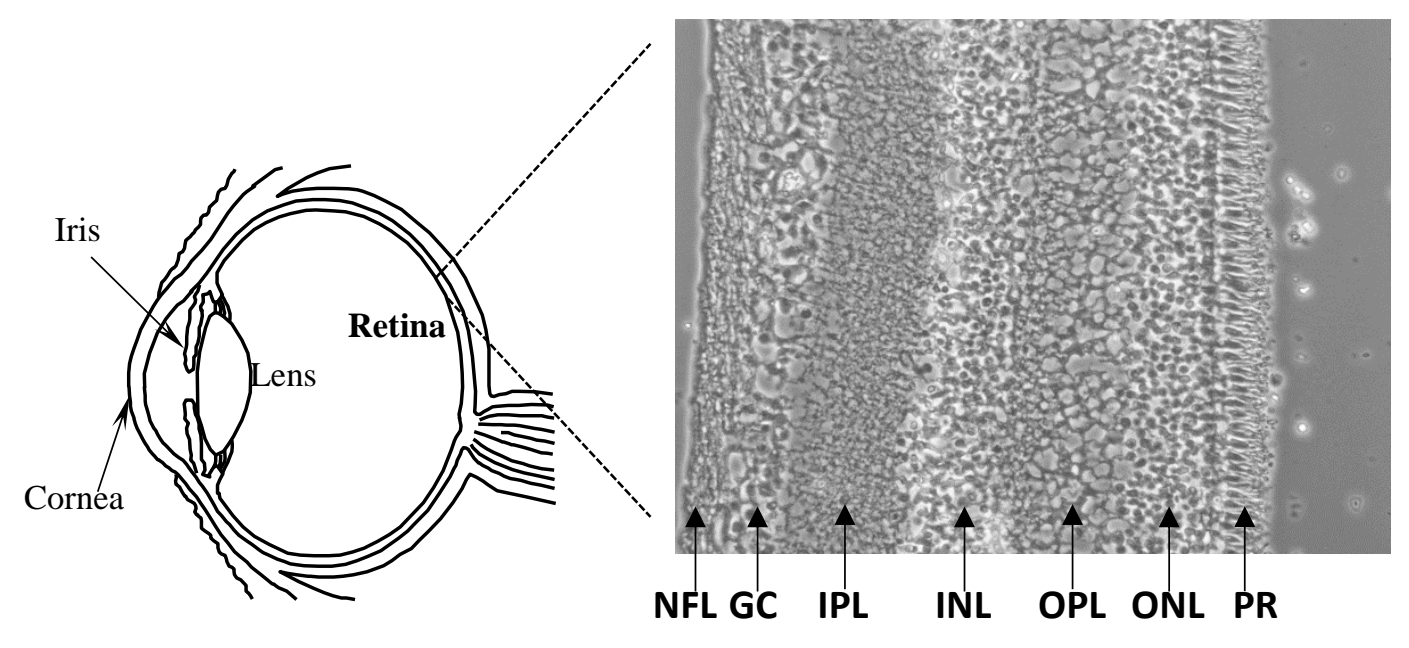

Figure 1 

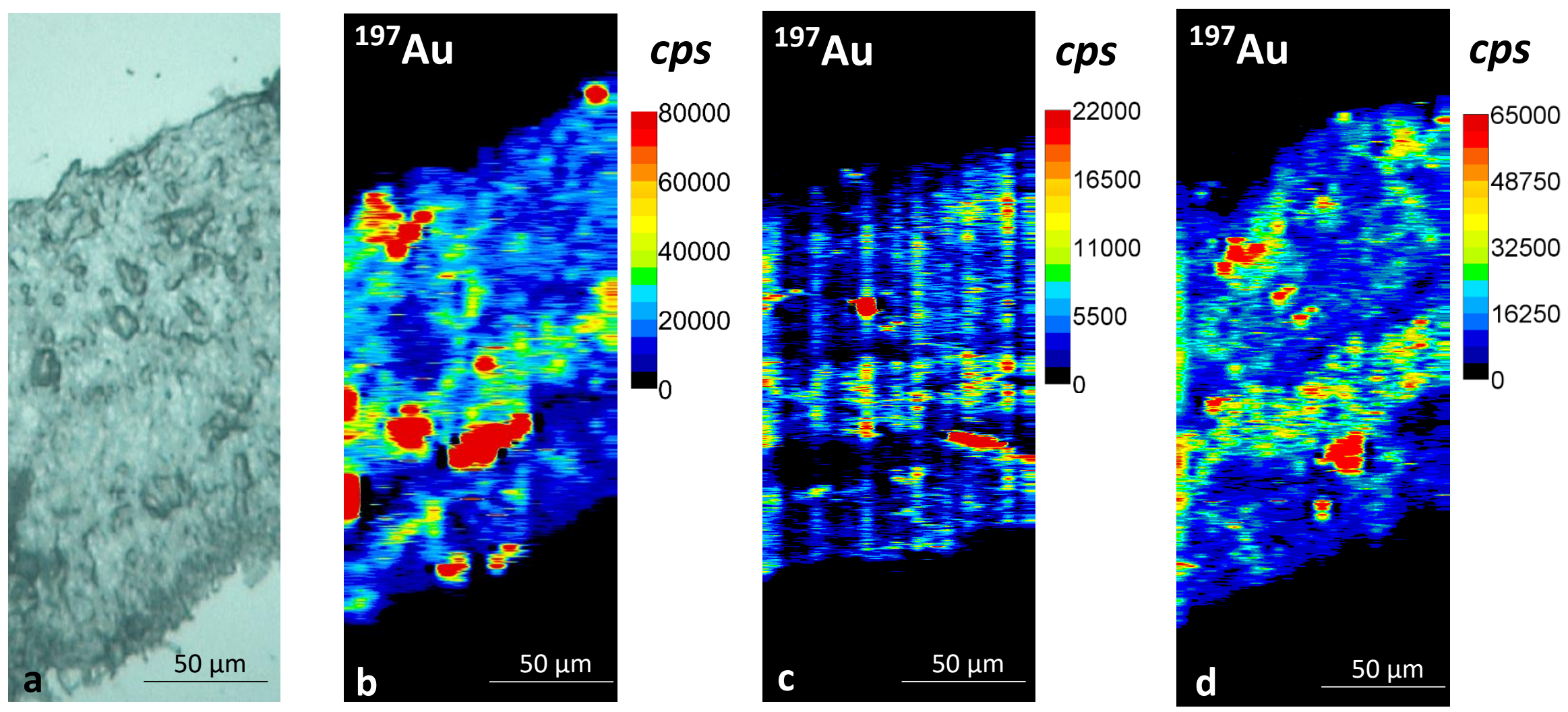

Figure 3 


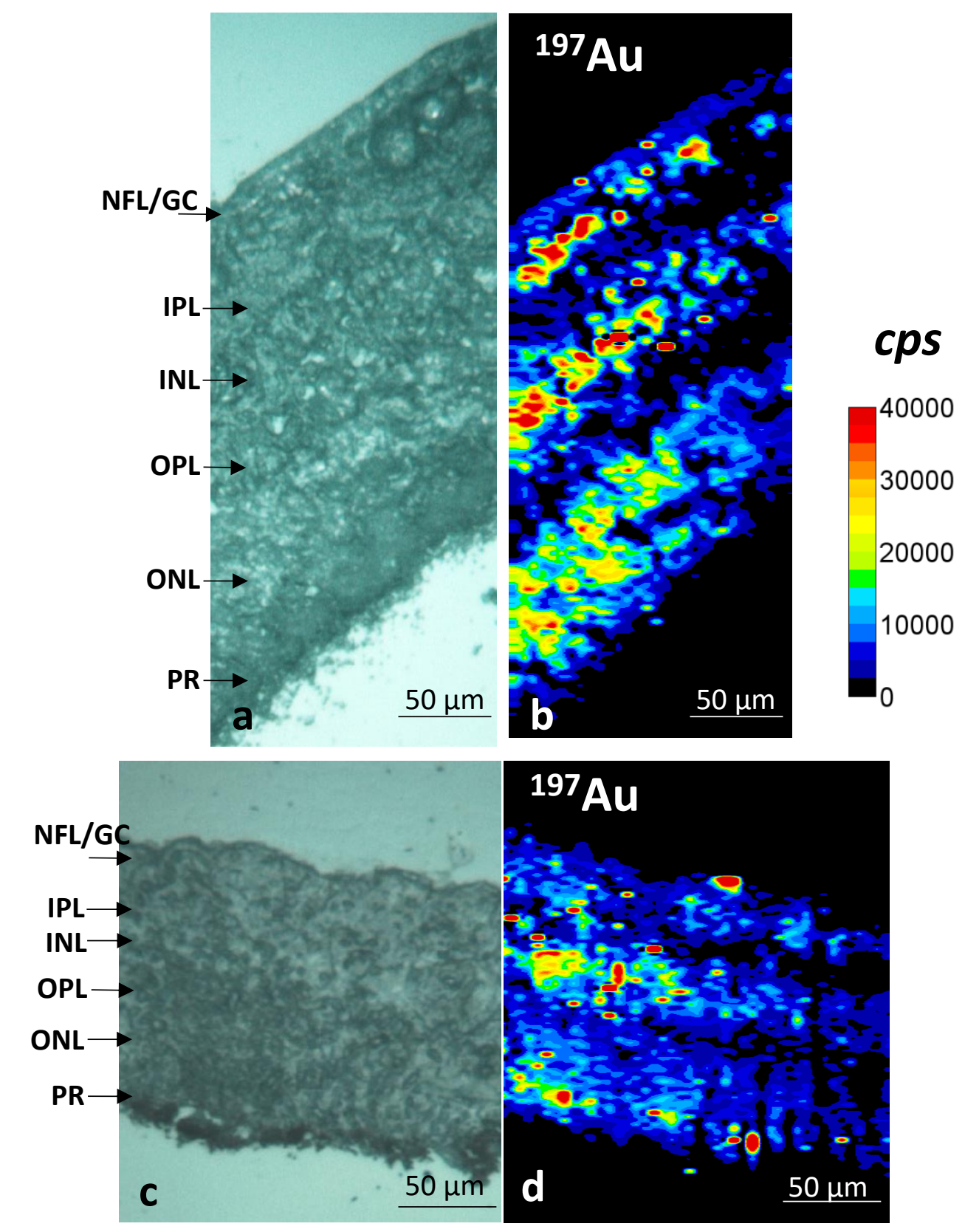

Figure 4 

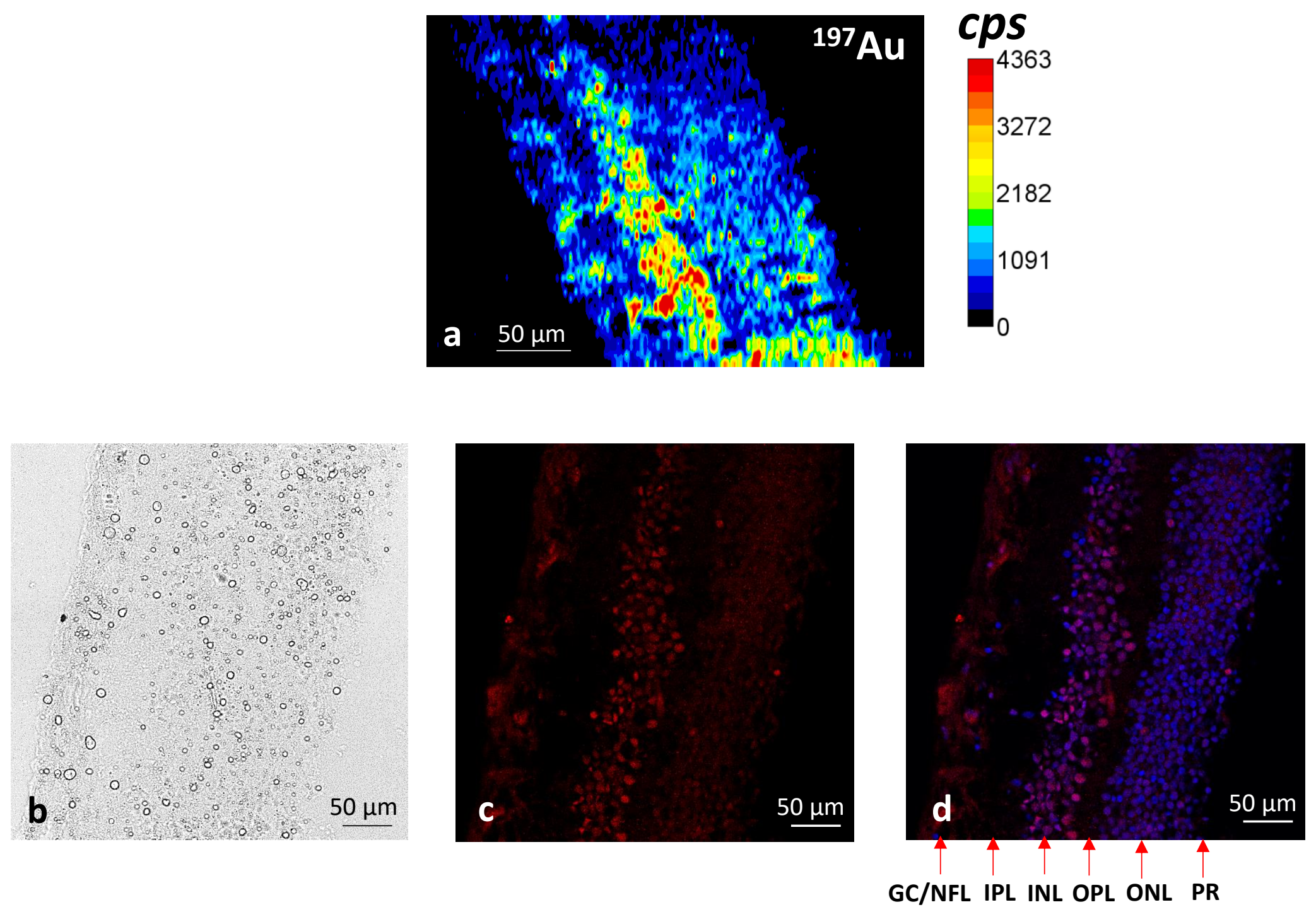

Figure 5 